\title{
Preparing a neurology department for SARS-CoV-2 (COVID-19)
}

\section{Early experiences at Columbia University Irving Medical Center and the New York Presbyterian Hospital in New York City}

\author{
Genna Waldman, MD, Richard Mayeux, MD, MS, Jan Claassen, MD, PhD, FNCS, Sachin Agarwal, MD, MPH, \\ Joshua Willey, MD, MS, Emily Anderson, MSN, RN, CNRN, Patricia Punzalan, MA, RN, NE-BC, \\ Ryan Lichtcsien, MA, Michelle Bell, MD, Serge Przedborski, MD, PhD, Christina Ulane, MD, PhD, \\ Kirk Roberts, MD, Olajide Williams, MD, Andrew B. Lassman, MD, Laura Lennihan, MD, and \\ Kiran T. Thakur, MD
}

Neurology ${ }^{\circledR}$ 2020;94:886-891. doi:10.1212/WNL.0000000000009519

Beginning in December 2019, a novel coronavirus, SARS-CoV-2 (COVID-19), began spreading rapidly throughout China and now is a global pandemic, with cases reported in over 192 countries and territories worldwide. Clinically, COVID-19 ranges from a mild, self-limiting respiratory illness to severe progressive pneumonia and multiorgan failure. The first COVID-19 case was reported at the beginning of March in New York City (NYC), and now just 3 weeks later, NYC and its suburbs have over 5\% of global cases. Worldwide, there is a rapid increase in the number of cases daily, including the number of patients requiring hospitalization and intensive care support.

Although our internal medicine, emergency department (ED), pulmonary/critical care, and anesthesiology colleagues are at the frontlines, neurologists are playing a critical role in patient care. Here, we describe the initial steps our department has taken to prepare for the COVID-19 outbreak. We highlight some of the steps neurology departments should urgently consider to prepare for an increased volume of patients with COVID-19 in their hospital system. This article provides a comprehensive guide for other neurology departments in terms of preparation for an influx of COVID-19-positive patients into their hospital system.

\section{General departmental initiatives}

As a department, we began holding routine meetings to prepare for COVID-19 in mid-February. Multidisciplinary meetings are held with key staff including nursing leadership, intensive care leadership, inpatient and outpatient neurology department leaders, and departmental administrative leadership (table 1). At the beginning of March, we held webcasts to our department weekly, given the restrictions for large in-person gatherings to provide updates on inpatient and outpatient clinical care activities, departmental research ramp down, human resources issues, and updates on hospital and public health guidelines including key epidemiologic information around COVID-19. There was an opportunity for departmental members including support staff to ask questions around work-related concerns.

Providing mental health support for the challenges we all face during this time due to social distancing and separation, child and elder care, financial, and clinical pressures was identified as an early critical component of our efforts. In addition to departmental neuropsychologists volunteering to provide free private counseling services, hospital-wide free telemental health support has also been made accessible to our department.

\section{Correspondence}

Dr. Thakur

ktt2115@cumc.columbia.edu
MORE ONLINE

COVID-19 Resources

For the latest articles, invited commentaries, and blogs from physicians around the world NPub.org/COVID19

From the Department of Neurology (G.W., R.M., J.C., S.A., J.W., R.L., M.B., S.P., C.U., K.R., O.W., A.B.L., L.L., K.T.T.), Neurological Institute, Columbia University Irving Medical Center; and New York Presbyterian Hospital (G.W., R.M., J.C., S.A., J.W., E.A., P.P., R.L., M.B., S.P., C.U., K.R., O.W., A.B.L., L.L., K.T.T.), New York, NY.

Go to Neurology.org/N for full disclosures. Funding information and disclosures deemed relevant by the authors, if any, are provided at the end of the article. 


\section{Glossary}

ED = emergency department; EMU = epilepsy monitoring unit; ICU = intensive care unit; IP\&C = infection prevention and control; NICU = neurocritical care unit; PPE = personal protective equipment; PUI = persons under investigation.

\section{Inpatient neurology service preparation}

\section{Inpatient neurology services}

During the early phase of our preparations, nursing leaders on our neurology units provided training for donning and doffing of personal protective equipment (PPE), nasopharyngeal sampling technique, review of protocols for patients who are persons under investigation (PUIs), and screening of our patients for possible COVID-19 symptoms. Hospitalbased guidelines are reviewed regularly. A checklist that the nurses completed is performed for all patients admitted to our units for possible COVID-19 symptoms. As community spread continued to rise, this checklist is now performed daily on all our inpatients. A COVID-19 binder was created on each unit to compile COVID-19-related documents including clinical guidelines, hospital protocols, and policies and our daily operations. A daily nursing huddle occurs to share information on COVID-19 and discuss PUI and COVID-19-positive cases on the unit. All trainees and inpatient neurology team members were trained in the same manner regarding proper PPE use, protocols for PUIs, and education around caring for patients with COVID-19 routinely.

Inpatient leadership and our chief resident developed a schedule to scale down our inpatient services to necessary staff including resident trainees (figure). Backup schedules and defined skills for redeployment (inpatient clinical, outpatient clinical, administrative, and language skills) were performed for trainees, neurohospitalists, and the neurocritical care team. Medical students and observers were removed from clinical services as was mandated by our hospital in early March. All teams practice social distancing when rounding and teaching is occurring in workrooms and not at the bedside. We minimized the number of team members entering patients' rooms to the attending for PUIs or those who were COVID-19 positive. We are bundling orders and adjusting routine care (i.e., laboratory draws, the frequency of neurologic checks, and timing of medication administration) to the minimum to provide adequate care while being conscientious of nursing exposure time in PUI and COVID+ rooms.

All elective admissions for nonurgent purposes were canceled in early March, and our epilepsy monitoring units (EMUs) were closed in both pediatrics and adult services. All urgent admissions and possible transfers were screened via phone for possible COVID-19 symptoms (including family members living in the same household) and accepted only if we could provide urgent management not available elsewhere. Rescreening for possible COVID-19 symptoms occurred when a patient arrived from an outside hospital or was directly admitted to our inpatient unit. If a patient was unable to answer questions regarding symptomology, which is the case in many of neurologic patients, we assumed that these patients may have COVID-19 infection during ongoing community spread and considered them a PUI in consultation with our infection prevention and control (IP\&C) experts. All COVID-19-positive patients were centralized to designated hospital units and specialized COVID-19 teams as the pandemic in New York continues to rapidly evolve. Patients with primary neurologic conditions who are COVID-19 positive or PUIs remain on our neurology services. Thus, training of PPE donning and doffing and PUI protocols were essential for our inpatient team members.

\section{Neurology consult services}

On our neurology consult services, we transitioned to curbside consultations, reserving in-person consultations for urgent inpatient issues and ED consults (i.e., new brain hemorrhage, acute stroke consults, and ongoing seizures). All EEGs ordered by non-neurology teams for PUIs and COVID-19-positive patients were required to be approved by our neurology consult teams to avoid unnecessary studies in the context of limited PPE and to protect EEG technicians. We subsequently developed mechanisms to expand our inpatient teleneurology services to our EDs and inpatient services.

Acute stroke care protocol in the ED includes temperature check, oxygen saturation measurement, and COVID-19 symptom screening before performing the NIH Stroke Scale. If the patient cannot answer the screening questions, we assume the patient is COVID-19 positive requiring the use of PPE. The availability of PPE is an ongoing challenge in NY and many other regions of the country.

We changed our tissue plasminogen activator, thrombectomy, intracranial hemorrhage, and subarachnoid protocols across the hospital system enterprise to concentrate care, allowing nursing care to focus on the COVID-19 surge of patients in the ED. Stroke care coordination across NYC centers has been essential with frequent citywide meetings involving neurointerventional radiologists, neurocritical care directors, stroke team leaders, and neurosurgery.

\section{Neurocritical care unit}

Currently, approximately $20 \%$ of our inpatient COVID19-positive patients require intensive care unit (ICU) support, and thus, a significant number of COVID-19-positive patients have been moved to the care in neurocritical care unit (NICU). Our ICU director frequently coordinates with hospital ICU directors to optimize the care of critically ill 
Table 1 Interdisciplinary meetings in the neurology department

\begin{tabular}{|c|c|}
\hline Interdisciplinary meetings and attendees & Select topics of discussion \\
\hline $\begin{array}{l}\text { Neurocritical Care } \\
\text { Critical Care Attendings across departments } \\
\text { Neurology Inpatient Attending Director } \\
\text { Neurohospitalist Attendings } \\
\text { ICU Nurse Managers } \\
\text { Step Down Unit Coordinators } \\
\text { Step Down Unit Nurse Managements } \\
\text { Neurology Chief Resident }\end{array}$ & $\begin{array}{l}\text { Alignment of hospital initiative of cohort patients with COVID-19 } \\
\text { Align with hospital initiative of increasing ICU beds } \\
\text { Education on COVID-19 specific airway and ventilator management and research treatments } \\
\text { Screening protocol for the altered and aphasic patient } \\
\text { Training on PPE donning and doffing } \\
\text { Protocol for increasing step down unit care for nonintubated ICU patients } \\
\text { Increase deployment of residents from neurology and neurosurgery departments to align with } \\
\text { care for increasing volume and medical complexity }\end{array}$ \\
\hline $\begin{array}{l}\text { Consult Service } \\
\text { Inpatient Attending Director } \\
\text { Neurohospitalist Attendings } \\
\text { Stroke Attendings } \\
\text { Neurology Chief Resident } \\
\text { Pediatric Neurology Consult Attendings }\end{array}$ & $\begin{array}{l}\text { Addition of temperature and } \mathrm{O}_{2} \text { saturation measurement to the stroke code vitals } \\
\text { Screening protocol for the stroke responder and consult resident in the ED } \\
\text { Training on PPE donning and doffing } \\
\text { Conversion to telephone consults } \\
\text { Implementation of teleneurology consultations } \\
\text { Minimize resident and attending staffing to essential personnel }\end{array}$ \\
\hline $\begin{array}{l}\text { Inpatient Meetings } \\
\text { Inpatient Attending Director } \\
\text { Neurohospitalist Attendings } \\
\text { Stroke Attendings } \\
\text { Patient Care Directors } \\
\text { Nurse Management } \\
\text { Neurology Chief Resident }\end{array}$ & $\begin{array}{l}\text { Screening protocol implementation for the outside hospital transfer and ED patient } \\
\text { Nurse training on daily screening checklist } \\
\text { Training on PPE donning and doffing } \\
\text { Minimize resident and attending staffing to essential personnel } \\
\text { Limit personnel bedside, resident teaching conducted in workrooms }\end{array}$ \\
\hline $\begin{array}{l}\text { Ambulatory Neurology } \\
\text { Outpatient Attending Directors } \\
\text { Faculty Practice Administrative Director } \\
\text { Inpatient Attending Director } \\
\text { Neurology Chief Resident }\end{array}$ & $\begin{array}{l}\text { Full conversion to telemedicine visits } \\
\text { A policy requiring Chairman review and approval for in-person outpatient visits } \\
\text { Screening protocol and education to staff and providers for patients approved to come for in- } \\
\text { person evaluation } \\
\text { Defer nonemergent diagnostics tests } \\
\text { Resident redeployment from outpatient clinical shifts to in patient essential clinical shifts }\end{array}$ \\
\hline $\begin{array}{l}\text { Inpatient to Outpatient Transition (Discharges) } \\
\text { Outpatient Attending Directors } \\
\text { Faculty Practice Administrative Director } \\
\text { Inpatient Attending Director } \\
\text { Neurohospitalist Attendings } \\
\text { Stroke Attendings } \\
\text { Neurology Chief Resident }\end{array}$ & $\begin{array}{l}\text { Inpatient checklist of patient information to provide to the outpatient scheduler } \\
\text { Implementation of rapid telemedicine visits for hospital discharges }\end{array}$ \\
\hline $\begin{array}{l}\text { Bi-Weekly Department Announcement } \\
\text { Neurology Chairman } \\
\text { Chief Financial Officer } \\
\text { Inpatient Attending Director } \\
\text { Faculty Practice Administrative Director }\end{array}$ & $\begin{array}{l}\text { Institution updates on hospital initiatives } \\
\text { Education on symptoms and stay home policy if any symptoms present } \\
\text { Work from home policy } \\
\text { Telemedicine protocol updates } \\
\text { Travel restrictions policy review } \\
\text { Research updates }\end{array}$ \\
\hline
\end{tabular}

Abbreviations: $E D$ = emergency department; ICU = intensive care unit; PPE = personal protective equipment.

patients with COVID-19. There has been rapid development of protocols around the safe management of critically ill patients with COVID-19 (i.e., intubation and other aerosolizing procedures and cardiopulmonary resuscitation). In early March, our NICU director and NICU faculty provided routine education and preparation to staff and trainees around acute respiratory distress syndrome management, guidelines for noninvasive positive-pressure ventilation and high-flow nasal cannula oxygen for patients with suspected or confirmed COVID-19, and ongoing clinical trials on antimicrobial and immunomodulatory treatments. Neurocritical care fellows were now deployed to maximize the care for critically ill patients with COVID throughout our hospital system. Our critical care rounding teams were split to include a COVID-focused team led by our neurointensivists, and a non-COVID-19 team focused on the COVID-negative neurologic critically ill patients lead by our neurovascular team (figure). Teams have been restructured to include essential personnel, with some team members providing remote support (i.e., pharmacists).

All intubations are performed by anesthesia for PUIs and COVID-19-positive patients. Early transfer of patients out of our NICU was prioritized with an emphasis on early tracheostomies and percutaneous endoscopic gastrostomy tubes, as well as early shunts. Our role in the prognosis and assessment of brain death is essential as neurologists, and protocols are in place with regard to patients with COVID-19. Making an accurate and reliable prognostic decision will reduce ventilator usage and conserve PPE resources. Guidelines from the American Heart Association (AHA) on neurologically related prognoses in patients with COVID-19 after cardiac arrest are being developed. Some of the early steps we are taking include establishing a neurologic examination by 1 intensivist, focusing on brainstem reflexes 48-72 hours after being off sedation, relying on spot 
Figure Personnel changes on neurology inpatient services during the COVID-19 pandemic

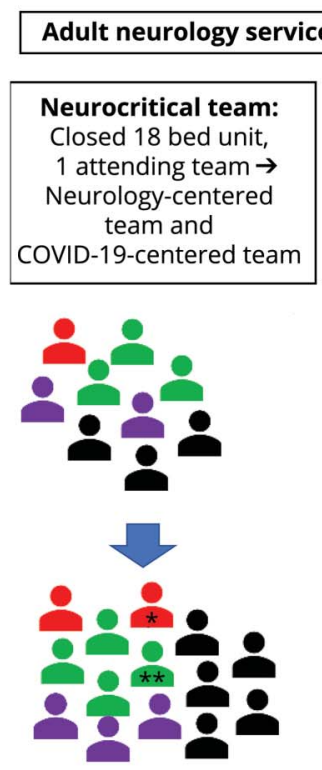

inpatient teams: Personnel over a 24-hour period

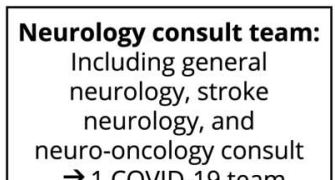

$\rightarrow 1$ COVID-19 team

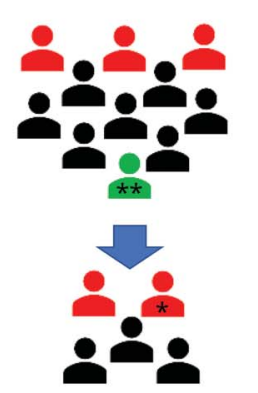

* COVID-19 stroke fellow in ICU, floor and consult role

** COVID-19 stroke attending in ICU, floor and consult role

and 1 NP team $\therefore$ Attending physician

$\therefore$ Fellow physician

2 Resident physician

$\therefore$ Physician extender (PA and NP)

patient neurology general team:

1 resident team

$\rightarrow 1$ COVID-19 team

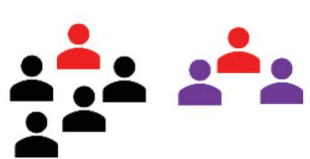

team:
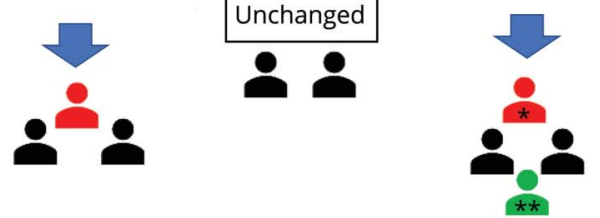

Inpatient stroke team

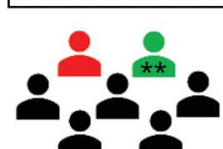

Pediatric neurology service inpatient teams: Personnel over a 24-hour period

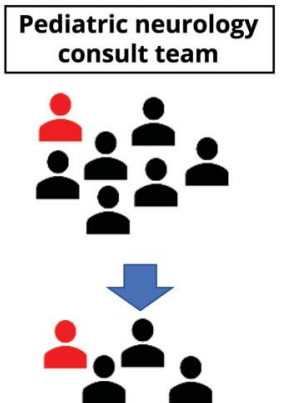

Epilepsy monitory unit: Personnel over a 24-hour period (closed during COVID-19)
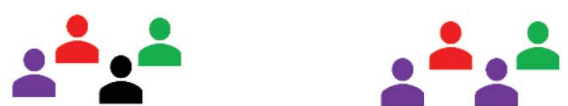

Adult

Pediatric

EEGs rather than continuous EEG in select cases, and obtaining neuroimaging and somatosensory evoked potentials if feasible.

As with neurology patients in the ED, there was an early recognition that our NICU patients will not be able to provide the history to screen in which we have stressed to our institution the necessity of considering testing for COVID-19 in those circumstances in consultation with IP\&C.

\section{Ambulatory neurology}

In early March, ambulatory staff including call center personnel and in-person patient greeters were trained to screen all patients and those accompanying the patient for possible
COVID-19 symptoms. Patients were contacted to schedule their visit on a telecommunication platform, and all patients were screened for symptoms. An ambulatory care protocol established by our hospital system was followed. Transition to teleneurology visits began for our outpatient practices in early March with the complete transition by mid-March for all new and established patients. Plans were immediately implemented to provide laptops and technical support to enable all outpatient practitioners to practice remotely. Webinars and guides for both patients and providers were distributed rapidly to enable as many visits as possible to continue uninterrupted. The university-wide ramp down in nonessential research activities has enabled us to increase the availability of telehealth sessions by providers who had 
previously dedicated significant time effort to research. Each division in our department created guidelines on which clinical scenarios warrant an urgent in-person visit. Any inperson visit must be approved by the division head and departmental leadership. Home EEG testing has been expanded. Botulinum toxin treatment for migraine has been continued, after the appropriate screening, to prevent relapse and avoid ED visits. Neurology infusion center patients are delayed when appropriate, transitioned to home infusions, or consolidated in the main hospital infusion center. Urgent postdischarge telemedicine appointment slots were established in all divisions to allow for expedited ED and inpatient discharge when appropriate.

All in-person visits in our resident clinic were also converted to telemedicine or, if patients do not have the technical capacity to participate in video visits, to a telephone visit. Residents performed telemedicine visits remotely and staff with an attending (also remote) by phone or by Zoom meeting. For the patients who needed to be seen urgently or who came in person for an appointment (if we cannot contact them), we established a rotating call system whereby 1 resident and 1 attending were available to come in within 30 minutes if needed.

\section{Research}

To minimize the number of individuals in the Medical Center and to be able to redeploy needed manpower, equipment, and supplies, all noncritical clinical and basic researches were ramped down in under guidance from the University. The implemented plan involved (1) setting up a 96-hour ramp down policy to complete all ongoing critical experiments, stopping all noncritical experiments, and preventing all new experiments; (2) establishing a list of a small number of essential research personnel onsite at any given day to assure the proper functioning of large equipment such as freezers or incubators, maintenance of animal husbandry, and control the integrity of research spaces; (3) redeploying research staff and post-docs, voluntarily and depending on skills, to assist teams working on critical tasks including COVID-19 research and testing; (4) pausing all clinical trials and observational studies that included patient contact, which was not related to COVID-19 or did not have direct patient benefit per our institutional review board (IRB) policy, and then eventually pausing all enrollment regardless of the potential for benefit. In addition, in discussion with the IRB and senior leadership concerning research administration, for patients already enrolled in clinical trials, potential or perceived risks of some protocol-specific events may outweigh the benefit and may be omitted, consistent with the Code of Federal Regulations. Once the ramp down plans were implemented, all research groups were encouraged to pursue all team activities and communications such as laboratory meetings, journal clubs, and thesis committee meetings remotely via internet-based video conferencing technology.

\section{Education}

With regard to educational activities, all medical student clerkships—including neurology_-were suspended in midMarch by the medical center, and a virtual curriculum was created for the remaining weeks of their rotation. It was arranged with the National Board of Medical Examiners that the shelf examination is to be performed remotely. For the residency and fellowships, conferences were continued via internet-based video conferencing technology.

\section{Conclusions: Team involvement and cohesion, well-being, challenges, and pathways ahead}

The importance of coordinated, multidisciplinary efforts to prepare neurology departments for the COVID-19 outbreak is essential. We have worked cohesively within the department, the hospital, and university to implement strategies to minimize the risk of COVID-19 transmission and perform the best of care for our patients. This has required ongoing adjustments and flexibility in our department. The need for close communication has been essential to the functioning of the department during these incredibly challenging times. There are certainly challenges ahead (table 2) during the unprecedented health crisis with further necessary adjustments and taking this pandemic seriously cannot be underemphasized for neurology departments across the country and world.

Table 2 Health care worker (HCW)-related issues during COVID-19

\begin{tabular}{ll}
\hline HCW at risk: preexisting conditions and age of providers & Recognizing preexisting conditions in our HCW \\
& Deploy the HCW to low-risk clinical duties, such as telemedicine clinic and home consult call
\end{tabular}

Quarantine

If any symptoms, HCW is not to work

Follow institution guidelines and contact Workforce Health and Safety for return to work guidance

Sick call

Daily review of shift assignments, for the quarantined staff to identify those available for back up sick pull 


\section{Acknowledgment}

The authors thank their pediatric neurology colleagues for their major role in departmental actions contributing to content in paper (Dr. Cigdem Akman, MD, and Dr. Danielle McBrian, MD).

\section{Study funding}

No targeted funding reported.

\section{Disclosure}

The authors report no relevant disclosures. Go to Neurology. org/ $\mathrm{N}$ for full disclosures.

\section{Publication history}

Received by Neurology March 27, 2020. Accepted in final form April 1, 2020.

Appendix Authors

\begin{tabular}{|c|c|c|}
\hline Name & Location & Contribution \\
\hline $\begin{array}{l}\text { Genna } \\
\text { Waldman, } \\
\text { MD }\end{array}$ & $\begin{array}{l}\text { New York Presbyterian } \\
\text { Columbia University Irving } \\
\text { Medical Center, New York }\end{array}$ & $\begin{array}{l}\text { Major role in } \\
\text { departmental actions } \\
\text { contributing to content in } \\
\text { paper and drafted and } \\
\text { revised the manuscript for } \\
\text { intellectual content }\end{array}$ \\
\hline
\end{tabular}

\begin{tabular}{ll}
\hline Richard & New York Presbyterian \\
Mayeux, MD, & Columbia University Irving \\
MS & Medical Center, New York
\end{tabular}

Major role in

departmental actions contributing to content in paper and revised the manuscript for intellectual content

\begin{tabular}{ll}
\hline Jan Claassen, & New York Presbyterian \\
MD, PhD, & Columbia University Irving \\
FNCS & Medical Center, New York
\end{tabular}

Major role in departmental actions contributing to content in paper and drafted the manuscript for intellectual content

\begin{tabular}{ll}
\hline Sachin & New York Presbyterian \\
Agarwal, & Columbia University Irving \\
MD, MPH & Medical Center, New York
\end{tabular}

Major role in departmental actions contributing to content in paper and revised the manuscript for intellectual content

\begin{tabular}{ll}
\hline Joshua & New York Presbyterian \\
Willey, MD, & Columbia University Irving \\
MS & Medical Center, New York
\end{tabular}

\section{Major role in}

departmental actions contributing to content in paper and revised the manuscript for intellectual content

\begin{tabular}{ll}
\hline Emily & New York Presbyterian \\
Anderson, & Columbia University Irving \\
MSN, RN, & Medical Center, New York \\
CNRN &
\end{tabular}

Major role in departmental actions contributing to content in paper and drafted the manuscript for intellectual content
Appendix (continued)

\begin{tabular}{|c|c|c|}
\hline Name & Location & Contribution \\
\hline $\begin{array}{l}\text { Patricia } \\
\text { Punzalan, } \\
\text { MA, RN, } \\
\text { NE-BC }\end{array}$ & $\begin{array}{l}\text { New York Presbyterian } \\
\text { Columbia University Irving } \\
\text { Medical Center, New York }\end{array}$ & $\begin{array}{l}\text { Major role in } \\
\text { departmental actions } \\
\text { contributing to content in } \\
\text { paper and drafted the } \\
\text { manuscript for } \\
\text { intellectual content }\end{array}$ \\
\hline $\begin{array}{l}\text { Ryan } \\
\text { Lichtcsien, } \\
\text { MA }\end{array}$ & $\begin{array}{l}\text { New York Presbyterian } \\
\text { Columbia University Irving } \\
\text { Medical Center, New York }\end{array}$ & $\begin{array}{l}\text { Major role in departmental } \\
\text { actions contributing to } \\
\text { content in paper }\end{array}$ \\
\hline $\begin{array}{l}\text { Michelle } \\
\text { Bell, MD }\end{array}$ & $\begin{array}{l}\text { New York Presbyterian } \\
\text { Columbia University Irving } \\
\text { Medical Center, New York }\end{array}$ & $\begin{array}{l}\text { Major role in } \\
\text { departmental actions } \\
\text { contributing to content in } \\
\text { paper and revised the } \\
\text { manuscript for intellectual } \\
\text { content }\end{array}$ \\
\hline
\end{tabular}

\begin{tabular}{ll}
\hline Serge & New York Presbyterian \\
Przedborski, & Columbia University Irving \\
MD, PhD & Medical Center, New York
\end{tabular}

Major role in

departmental actions contributing to content in paper and revised the manuscript for intellectual content

\begin{tabular}{|c|c|c|}
\hline $\begin{array}{l}\text { Christina } \\
\text { Ulane, MD, } \\
\text { PhD }\end{array}$ & $\begin{array}{l}\text { New York Presbyterian } \\
\text { Columbia University Irving } \\
\text { Medical Center, New York }\end{array}$ & $\begin{array}{l}\text { Major role in } \\
\text { departmental actions } \\
\text { contributing to content in } \\
\text { paper and revised the } \\
\text { manuscript for intellectual } \\
\text { content }\end{array}$ \\
\hline
\end{tabular}

\begin{tabular}{ll}
\hline Kirk Roberts, & New York Presbyterian \\
MD & Columbia University Irving \\
& Medical Center, New York
\end{tabular}

Major role in

departmental actions contributing to content in paper and revised the manuscript for intellectual content

\begin{tabular}{ll}
\hline Olajide & New York Presbyterian \\
Williams, MD & Columbia University Irving \\
& Medical Center, New York
\end{tabular}

Major role in departmental actions contributing to content in paper and revised the manuscript for intellectual content

\begin{tabular}{lll}
\hline Andrew & New York Presbyterian & Major role in \\
Lassman, & Columbia University Irving & $\begin{array}{l}\text { departmental actions } \\
\text { contributing to content in } \\
\text { MD }\end{array}$ \\
Medical Center, New York & $\begin{array}{l}\text { paper and revised the } \\
\text { manuscript for intellectual } \\
\text { content }\end{array}$
\end{tabular}

\begin{tabular}{lll}
\hline $\begin{array}{l}\text { Laura } \\
\text { Lennihan, } \\
\text { MD }\end{array}$ & $\begin{array}{l}\text { New York Presbyterian } \\
\text { Columbia University Irving } \\
\text { Medical Center, New York }\end{array}$ & $\begin{array}{l}\text { Major role in } \\
\text { departmental actions } \\
\text { contributing to content in } \\
\text { paper and revised the } \\
\text { manuscript for intellectual } \\
\text { content }\end{array}$ \\
\hline $\begin{array}{l}\text { Kiran T. } \\
\text { Thakur, MD }\end{array}$ & $\begin{array}{l}\text { New York Presbyterian } \\
\text { Columbia University Irving }\end{array}$ & $\begin{array}{l}\text { Major role in } \\
\text { departmental actions } \\
\text { contributing to content } \\
\text { in paper and drafted } \\
\text { and revised the }\end{array}$ \\
& & $\begin{array}{l}\text { manuscript for intellectual } \\
\text { content }\end{array}$ \\
& &
\end{tabular}




\section{Neurology}

Preparing a neurology department for SARS-CoV-2 (COVID-19): Early experiences at Columbia University Irving Medical Center and the New York Presbyterian Hospital in New York City

Genna Waldman, Richard Mayeux, Jan Claassen, et al. Neurology 2020;94;886-891 Published Online before print April 6, 2020 DOI 10.1212/WNL.0000000000009519

This information is current as of April 6, 2020

\section{Updated Information \&} Services

Citations

Subspecialty Collections

Permissions \& Licensing

Reprints including high resolution figures, can be found at: http://n.neurology.org/content/94/20/886.full

This article has been cited by 3 HighWire-hosted articles: http://n.neurology.org/content/94/20/886.full\#\#otherarticles

This article, along with others on similar topics, appears in the following collection(s):

All Clinical Neurology

http://n.neurology.org/cgi/collection/all_clinical_neurology All Health Services Research

http://n.neurology.org/cgi/collection/all_health_services_research

Information about reproducing this article in parts (figures,tables) or in its entirety can be found online at:

http://www.neurology.org/about/about_the_journal\#permissions

Information about ordering reprints can be found online:

http://n.neurology.org/subscribers/advertise

Neurology ${ }^{\circledR}$ is the official journal of the American Academy of Neurology. Published continuously since 1951, it is now a weekly with 48 issues per year. Copyright @ 2020 American Academy of Neurology. All rights reserved. Print ISSN: 0028-3878. Online ISSN: 1526-632X.

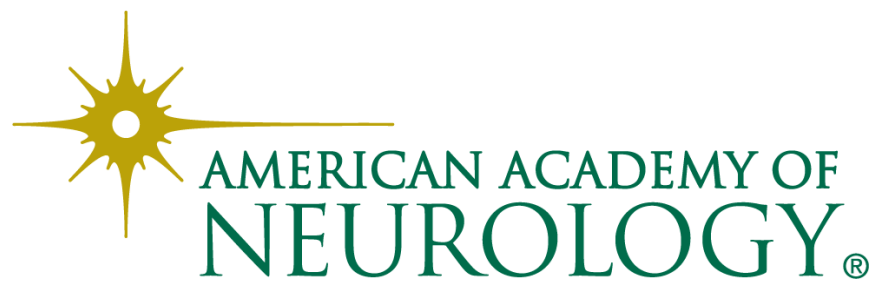

